\title{
A Blended Teaching Mode of University Mathematics Based on "Micro Class" and "Rain Class" under the Internet plus Background
}

\author{
Ying Li*, Wenrui Qu \\ Division of Mathematics and Artificial Intelligence, Jinan, China \\ Email: *ly200245@qlu.edu.com
}

How to cite this paper: Li, Y., \& Qu, W. R. (2021). A Blended Teaching Mode of University Mathematics Based on "Micro Class" and "Rain Class" under the Internet plus Background. Advances in Applied Sociology, 11, 716-723.

https://doi.org/10.4236/aasoci.2021.1112058

Received: November 17, 2021

Accepted: December 26, 2021

Published: December 29, 2021

Copyright $\odot 2021$ by author(s) and Scientific Research Publishing Inc. This work is licensed under the Creative Commons Attribution International License (CC BY 4.0).

http://creativecommons.org/licenses/by/4.0/ (c) (i) Open Access

\begin{abstract}
In the context of the Internet, the popularity of smart phones has brought an impact on the traditional mathematics teaching mode. This paper studies the blended teaching mode of "micro class" and "rain class" based on the Internet, which makes up for the shortcomings of the traditional teaching mode and improves the learning effect.
\end{abstract}

\section{Keywords}

Micro Class, Rain Class, Blended Teaching, University Mathematics

\section{Introduction}

With the wide spread of smart phones, the mobile Internet has challenged traditional teaching mode. New teaching mode has emerged. The reform of Internet plus education represented by "Micro class" and "Rain class" has become a hot topic in academia and teaching practice. Let's first look at the research status of "Micro class" at home and abroad and the research status of "Rain class".

"Micro class" refers to a teaching method in which teachers teach around a single teaching task such as a certain knowledge point or skill in the process of education and teaching inside and outside the classroom. Its core content is classroom teaching video (lesson fragments). At the same time, it also includes teaching design, material courseware, teaching reflection, practice test and student feedback related to the teaching theme, teachers' comments and other auxiliary teaching resources.

"Micro class" is an imported product, which originated from Khan College. In foreign studies, the terms related to "micro curriculum" include minicourse, micro curriculum, microlesson and so on, but their research orientation of "mi- 
cro curriculum" is not exactly the same. For example, the Affiliated School of Iowa University in the United States first proposed the mini course in 1960, which can also be called short-term course or course unit; the microlessons research project implemented by the Ministry of Education of Singapore in 1998 involves a number of curriculum fields. Its main purpose is to train teachers to build micro courses. The courses are generally 30 minutes to 1 hour. The teaching objectives are simple and focused, pay attention to the creation of learning situations, resources and activities, and provide effective learning support for students. At the same time, it also provides a series of supports for teachers to help them carry out specific teaching design. In July 2004, the teacher television channel (https://www.teacher.tv/) was launched in the UK. The video duration of each program is 15 minutes. After the channel was launched, it was widely recognized by teachers. The accumulation of resources reached 350,000 minutes; in the autumn of 2008, David Penrose, a "one minute professor" of San Juan College in New Mexico, became famous for initiating the "micro course" of "one minute micro video", which has a wide impact. Its core idea is to require teachers to closely connect teaching content with teaching objectives, so as to produce a "more focused learning experience". It can be seen that foreign countries pay more and more attention to the research of "micro curriculum" and "micro video".

"Rain class" is a free teaching software developed by Online Education Office of Tsinghua University and online. It integrates PPT, MOOC and mobile phone WeChat. Now it has been upgraded to version 2.2, giving a new experience to every link before, during and after class, releasing the energy of teaching and learning, and effectively promoting Internet plus. The practice of teaching reform indicates that the informationization of teaching in universities will enter a stage of "Internet + blackboard + mobile terminals".

Using the "Rain class", teachers can design short and concise "micro courseware" suitable for mobile phone screen, preview task list, review task list and exercise questions, and push them to students' mobile phones through wechat platform, so as to facilitate students' mobile learning anytime and anywhere after class. For slides that cannot be understood in the courseware, students can mark "don't understand" and feed back to teachers, or they can study repeatedly by themselves. In the classroom, teachers and students can conduct real-time interaction and bullet screen communication through the "Rain class". In addition, "Rain class" provides teachers and students with all-round and multi-dimensional data support, personalized reports reflecting students' learning progress and learning situation, and automatic task reminders, making the whole teaching process more intelligent. More than 10,000 schools around the world are using the "Rain class", and many courses adopt the wisdom classroom under the "Rain class" in teaching, with good results (https://www.yuketang.cn/).

\section{Research Significance of Research}

Due to its own characteristics, the content of mathematics course is profound and the concept is abstract. In the face of limited class hours, there will be 
"cramming" teaching in the teaching. There is a lack of necessary interaction between teachers and students, it is difficult to mobilize students' enthusiasm in the teaching, the classroom atmosphere is not active enough, and the teaching effect is not ideal.

On the one hand, the problems in college mathematics teaching:

1) In teaching, there are few class hours and many contents (Sun, 2020). In class, the teacher is busy catching up with the progress, leaving less time for students to think deeply.

2) There are differences in acceptance among students ( $\mathrm{Xu}, 2015)$.

3) In terms of course structure, mathematics course has strict logical thinking (Sun, 2020). The description of some concepts and theorems in the textbook is too complex, which makes beginners flinch.

4) Most of the college mathematics courses are taught in large classes. Most of the interaction between students and teachers can only stay in the students' collective answers or teachers' self questions and answers (Sun \& Yang, 2010). Teachers cannot fully understand the students' mastery of the explained knowledge.

On the other hand, college mathematics teaching is facing a new situation. With the rapid development of information technology, college teachers are strongly aware that it is essential to integrate information network technology into ordinary teaching (Ma \& Zhang, 2021). "Micro class" and "Rain class" can greatly supplement the shortcomings of traditional teaching and change students' learning methods. However, fundamentally, we still need to appropriately change the teaching content and the thinking mode of today's college students, The way of learning and life has changed, but our educators speak outdated languages and educate a group of new people in the digital age. One of the important skills for today's teachers is to grab students' attention with mobile phones in class.

Based on the above reasons, we use the "rain class" teaching mode in the "Internet plus" era, which combines online and offline teaching mode. It is the combination of the advantages of traditional classroom teaching and digital teaching, the combination of the advantages of online teaching system and physical classroom teaching system, including multiple combinations of different learning theories, learners, teachers, learning environment and teaching methods, which can solve the above problems. The blended teaching mode based on "Micro class" and "Rain class" challenges the learning mode of traditional classroom. The traditional classroom pays more attention to the amount of knowledge imparted ( $\mathrm{Lu} \& \mathrm{Tao}, 2019)$. Students rarely have time to explore and think independently, while the "Rain class" pays attention to each student's knowledge level, learning situation, how teachers realize personalized guidance, etc. This model has achieved three changes: students learn from passive learning to active learning, and teachers' teaching mode is changed from teaching mode to inquiry mode, and students are passively learning to group learning.

This blended teaching mode has many advantages: 
1) Online courses can be studied repeatedly;

2) Improve students' learning efficiency;

3) The learning effect is transparent and students can feed back in time;

4) Classroom teaching is mainly based on discussion to cultivate students' expression and thinking ability (Zheng, 2018).

\section{The Main Contribution and Innovation of Research}

Firstly, this paper analyzes the characteristics of mathematics curriculum and determines the goal of mixed teaching mode reform, and then focuses on this goal to carry out online and offline teaching method reform research through micro class design and classroom teaching design. Among them, the theoretical path mainly includes micro course selection and teaching design, online and offline teaching content selection and classroom teaching method reform, and the reform of students' scientific and systematic comprehensive evaluation. These reforms serve the core goal of how to better learn.

Innovation: relying on the rain classroom, we will provide convenience for online learning through the construction of micro class library and test question library, reform the way of classroom teaching, achieve the perfect combination of online and offline learning, truly take students as the main body and return the classroom to students, improve students' autonomous learning ability, activate the classroom atmosphere, stimulate learning interest and improve the efficiency of mathematics learning.

\section{Preparations for the Implementation of Blended Teaching}

\subsection{Preparations for the Implementation of Blended Teaching}

Actively change the teaching concept and strengthen the cultivation of students' information literacy.

The times and students' characteristics are constantly changing. Teachers should update their teaching ideas in time and actively carry out teaching reform in order to provide better education for students in higher vocational colleges (Jia, 2019). In the era of "Internet plus", teachers should be able to skillfully use various teaching multimedia, and carry out the teaching design of "Internet plus" background, so as to achieve a blended teaching goal.

The level of information literacy will directly affect the learning effect of hybrid teaching. The school should actively build an information campus, change the way of knowledge transfer, improve students' information literacy and develop in a balanced way.

According to the needs of students and the characteristics of mathematics knowledge taught, the teaching contents are sequenced and selected.

Teachers should choose the part suitable for e-learning according to their grasp of students' characteristics and knowledge characteristics. Teachers should boldly screen and sequence the teaching contents in the teaching materials. According to the characteristics of the students in the teaching class and the cor- 
responding professional characteristics, under the condition of grasping the learning system, teachers should not stick to the confinement of teaching materials and fixed thinking, and select online contents based on the needs of students.

Design and record micro courses for the above selected knowledge points.

For the listed knowledge points, you can borrow excellent micro courses on the Internet. If some knowledge points do not have corresponding micro courses, you can design micro courses by yourself for recording.

The construction of "Rain class" class, such as the construction of question bank, chapter detection test questions, and supporting exercises of difficult and error prone points in each class.

\subsection{Specific Cases of Building a Blended Teaching Model of College Mathematics Based on "Micro Class" and "Rain Class"}

Select the knowledge points in specific chapters to design online content.

Do a good job in the teaching design before, during and after class.

Enhance the communication between teachers and students in the classroom and pay attention to the cultivation of cooperative learning ability.

Build a reasonable evaluation method to stimulate the improvement of students' self-learning ability.

The smooth development of blended teaching depends on the effect of pre class learning. In the face of mathematics with fear, whether students can patiently complete pre class learning through multimedia is the most critical problem. In order to better promote and motivate the improvement of students' self-learning ability, in addition to the teaching design suitable for students' characteristics mentioned above, there also needs to be a reasonable and mixed teaching supporting evaluation method. In the mixed teaching mode, students' evaluation should adopt a diversified evaluation system, and the process and comprehensive evaluation should be combined.

\subsection{Analysis of Teaching Effect of College Mathematics Blended Teaching Mode Based on "Micro Class" and "Rain Class"}

1) Tracking data report of Hybrid Teaching Mode.

2) Questionnaire and data analysis on the use of blended teaching mode.

\subsection{Effect of Mixed Teaching}

\subsubsection{Highlight the Main Role of Students and Reform the Traditional Teaching Mode}

Because college mathematics curriculum has a high degree of abstraction and strict logic, if we still adhere to the traditional "indoctrination" and "one-way" teaching mode (Xi et al., 2020), students will be more afraid of mathematics class and escape from the classroom. Actively explore the student-centered teaching mode, let students participate in classroom teaching as much as possible, and regard knowledge transfer as a two-way interactive behavior of "teaching" and 
"learning", and teachers should give full play to their guiding, helping and encouraging role in students' autonomous learning. Actively explore and adopt diversified teaching methods, carry out online and offline mixed teaching mode with the help of "Micro classes" under the "Rain class", and transform teachers' teaching activities into a process in which students actively seek knowledge, make independent choices and deepen themselves. At the same time, we can also pay attention to the differences between students, encourage individual personality development, implement classified guidance, and fully explore students.

\subsubsection{Make Full Use of "Micro Classes" to Improve Classroom Efficiency}

The lack of learning motivation of college students is the key to the implementation of hybrid teaching model. Especially for the online learning part before class (i.e. flipped classroom part) (Zhang \& Du, 2020), establish an appropriate incentive system to improve students' enthusiasm and initiative for online learning.

\subsubsection{Reasonable Comprehensive Evaluation System}

"Rain class" provides students' online learning data, effective statistics of attendance rate by roll call system, data records of interactive discussion with teachers, and performance records of knowledge point detection and unit knowledge detection, which can be used as an effective reference for process learning. As the main place of learning, it is the classroom, and students' classroom performance is also a part of the evaluation system. The evaluation of students cannot judge the whole learning situation of students only by the last test paper. Establish a process based comprehensive evaluation system to evaluate students' learning effect objectively and scientifically.

\section{Key Issues to Be Solved}

\subsection{Reasonable Allocation of Online and Offline Classes and Contents}

The blended teaching mode needs to reasonably select and allocate teaching content as online and offline parts, which content is suitable for online teaching, which content is suitable for offline teaching, and how to reasonably allocate online and offline teaching hours in order to achieve the best teaching effect.

\subsection{Monitoring System for the Quantity and Effectiveness of Online Learning}

Online learning needs to mobilize students' enthusiasm and initiative for mathematics courses and be able to study independently. The self-control and initiative of college students still need guidance, but also need to establish a strong supervision system and combine it with the final learning evaluation.

\subsection{Comprehensive Use of Various Teaching Methods in Classroom Teaching}

The online teaching content decomposes the difficulties and key points in class- 
room teaching. After students understand the learned content, they put forward higher requirements for offline, that is, classroom teaching. The teaching content and teaching methods need to be changed accordingly. In the classroom teaching, a variety of teaching methods, such as heuristic, problem-based, inquiry, boppps and other teaching modes, make the classroom teaching dynamic, better carry out the teaching interaction between teachers and students, and make the mathematics classroom full of fun of communication, exploring and solving problems.

The advent of the network age has revolutionized the methods and ways for people to obtain information. For students, textbooks are no longer the only source of knowledge, and teachers are no longer the knowledge owners and disseminators who live above the palace of knowledge. Under the network environment, the younger generation of college students has some technical advantages compared with the group of teachers. In order to meet the urgent requirements for the cultivation of innovative talents with high requirements for Applied Talents in the new era, it is necessary to explore a new teaching model. This hybrid teaching is suitable for this change of the times, stimulates students' interest in learning and improves the learning efficiency of mathematics.

This hybrid teaching mode integrates the dual advantages of classroom and network, combines the traditional teaching mode and information-based teaching mode, realizes mutual supplement and mutual promotion, changes the traditional "teacher oriented" teaching structure, realizes the dual main teaching structure of "teacher led and student-centered", forms a new teaching mode and improves the classroom teaching effect.

\section{The Limitation of Research}

Finally, the bottleneck problems encountered in the research of this hybrid teaching model are considered.

1) Due to the characteristics of college mathematics, online classes should not be too many. How to set the proportion of online courses is the most appropriate.

2) How to supervise and evaluate the effect of students' online learning is more appropriate.

3) Rain class can only use mobile phone function, and does not support the editing of mathematical formulas. Online exercises are mostly multiple-choice questions, which limit the diversity of questions, and the investigation of students' learning effect is not objective and accurate.

4) How to solve the problem of teacher-student interaction in the process of large class teaching.

\section{Acknowledgements}

This work is supported by Center for Research and Development of Mathematics Teaching in Universities "research on the teaching design of ideological and 
political education in university mathematics curriculum" (Project No. CMC20210407), and Shandong Education and teaching reform research project "research on the ideological and political practice of university mathematics courses under the background of Sanquan Education" (Project No. 20SJG039) and Qilu Institute of Engineering (Shandong Academy of Sciences) "research on the ideological and political practice of university mathematics courses under the background of Sanquan Education" (Project No. 2020szzx25).

\section{Conflicts of Interest}

The authors declare no conflicts of interest regarding the publication of this paper.

\section{References}

Jia, L. L. (2019). Exploration and Practice of University Mathematics Hybrid Teaching Mode Based on "Online and Offline": Taking Dianchi College of Yunnan University as an Example. Journal of Hubei Open Vocational College, 32, 134-135.

Lu, S. Q., \& Tao, Y. (2019). Based on the "Online and Offline" University Mathematics Hybrid Teaching Model. Education Modernization, 69, 29-31.

Ma, W., \& Zhang, J. (2021). Application of Blended Teaching Mode in Comprehensive English Course. Creative Education, 12, 647-652. https://doi.org/10.4236/ce.2021.123044

Sun, P., \& Yang, Q. S. (2010). Problems and Countermeasures in Higher Mathematics Teaching of Engineering in Higher Vocational Colleges. Journal of Heze University, 32, 118-121.

Sun, Y. (2020). Problems and Suggestions in Higher Mathematics Teaching. Journal of Liaoning Normal Colleges (Natural Science Edition), 22, 13-15.

Xi, P., Ma, R. X., Shi, C. S., \& Tang, L. G. (2020). Design and Implementation of Hybrid Teaching Characterized by Live Broadcasting. Journal of Higher Education, 15, 10-13.

$\mathrm{Xu}$, S. J. (2015). Exploration on Teaching Reform of Advanced Mathetatics Mode of Applied Innovative Talents Training. Managenent Observer, 30, 109-111.

Zhang, J., \& Du, S. R. (2020). The Connotation, Value Appeal and Implementation Path of Hybrid Teaching. Education and Management, 12, 11-13.

Zheng, X. J. (2018). The Exploration and Practice of the Mixed Teaching Mode of "College Mathematics" in Local Undergraduate Colleges and Universities under the Tide of Micro Course. Journal of Daqing Normal University, 38, 151-155. 